\title{
International Scientific Collaboration Links of Central Eastern European Countries Measured Through Publications
}

Andrea Magda Nagy

MTA-PE Networked Research Group on Regional Innovation and Development Studies, Hungary

\begin{abstract}
The countries of Central Eastern Europe (CEE) are lagging behind Western-Europe regarding scientific performance in the field of economics. A way to improve the quantity and quality of scientific output is to establish international scientific links with developed countries. The aim of this study is to analyze the international cooperation of Central and Eastern European countries in the field of economics. International scientific collaborations are measured through publications. The analyzed time period is 1996-2014. The used database is Scopus. Using network theory tools, it is shown that researchers from the CEE countries tend to publish more with researchers from Western Europe or the USA, rather than with researchers from the CEE region. It appears that geographical distance does not play a significant role in choosing international scientific collaboration partners. Policy decision makers should focus more on supporting and promoting research and educational mobility as these can help the CEE countries in the scientific catching-up process.
\end{abstract}

Keywords: scientific collaboration networks, research, economics JEL classification: A19, D85, 120

\section{Introduction}

Scientific collaboration has become a favorite topic in bibliometric research. The first comprehensive study on international collaboration using cooperativity measures has been published by Schubert and Braun and found a dramatic increase of international collaboration in publications of the Science Citation Index database (Schubert et al., 1990).

Scientific collaboration plays an important role in the production of new knowledge (Beaver, 2004).As stated in the EU Horizon2020, if research is to tap its potential, international cooperation is of critical importance (European Commission, 2014). Several definitions for scientific collaboration have been proposed. Laudel (2002) divided scientific collaborations into six categories. These are as follows: collaboration involving division of labor, service collaboration, and provision of access to research equipment, transmission of know-how, mutual stimulation, and trusted assessorship. Scientific collaborations can have many outcomes. One of its results is co-authored publications. Although co-authored publications are only one aspect of scientific collaboration, it is a useful and effective way to measure collaborations (see for example Beaver et al., 1978 or Lundberg et al., 2006). This study uses publications to measure scientific cooperation of Central Eastern European (CEE) countries in the field of economics.

The countries of the CEE region are lagging behind Western European and North American countries regarding their performance in social sciences (Radosevic, 
2014). A way to increase their scientific output is through scientific collaborations. International scientific cooperation can improve both productivity and impact of scientific performance of countries (see for example Glänzel et al., 200 1; Zhou et al., 2015).This is especially the case when one of the collaborating partners is a developed Western European or North American country and the other partner is a developing country (see for example Coupé, 2004).

The aim of this study is to analyze international scientific cooperation links of CEE countries using publication data from the field of economics. It is interesting to see whether these countries tend to publish more with their regional neighbors or with Western European or North American countries.

After a short introduction concerning relevant literature, the methodology of the analysis is presented. This is followed by showing the findings of the research. At the end of the study the main conclusions are summarized and possible future research is suggested.

\section{Methodology}

The countries of Central Eastern Europe are analyzed. The study focuses on the field of economics, econometrics and finance (in the study referred to as economics). The publication data of Hungary, the Czech Republic, Slovakia, Slovenia, Poland, Romania, Bulgaria and Croatia from 1996 to 2014 are taken in consideration.

Network theory tools are being used for this analysis. Countries are the nodes. Two nodes are linked together when there is a publication with the two countries (nodes) mentioned in its affiliation. This means that not only co-authored publications are taken in consideration, but all publications which have beside a CEE country, at least another country mentioned in the affiliation.

Network indices are used for analyzing the CEE countries' scientific cooperation in the field of economics. PageRank describes the position and importance of nodes in the network. Publication data for the eight CEE countries have been retrieved from Scopus for the 1996-2014. The links between countries (nodes) have been weighted according to the number of times the two countries are mentioned together in the affiliation of publications.

\section{Results}

The publication links of the CEE countries in the field of economics have been analyzed. The partner countries are grouped into nine regions, the Caribbean, South America, Oceania, North America, Middle East, Europe Central America, Asia and Africa. Figure 1 shows the regional distribution of the CEE countries' scientific partners. More than 73\% of the CEE countries' scientific collaboration is with countries from Europe. Countries of North America (United States of America and Canada) are also preferred. Publication links with countries from other continents are less in number. Almost $90 \%$ of the scientific collaboration of the countries analyzed are with European countries or the United States of America and Canada. 
Figure 1

Regional distribution of the Scientific Links of CEE Countries in the Field of Economics

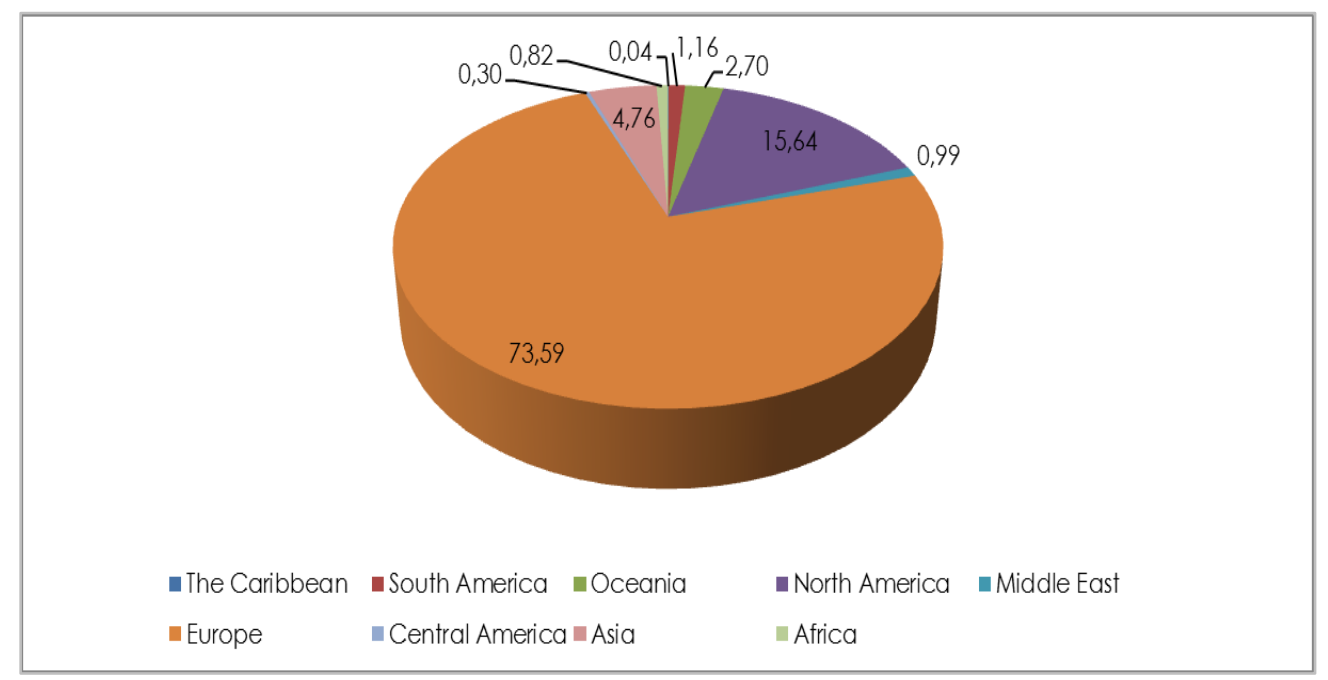

Source: Author's illustration

Central Eastern European countries tend to cooperate more with countries from Europe than with countries from other continents. It is interesting to see whether the CEE countries collaborate more with their regional neighbors or with other European countries. When looking at publication affiliations, there are more links between CEE and other European countries than between CEE and CEE countries (see Figure 2).

Scientific cooperation links between Central Eastern European countries compared to scientific cooperation links between Central Eastern European and other European countries are analyzed. The ratio for Poland is the lowest, while the highest is for Slovakia. This means that, except Slovakia, the CEE countries tend to publish less with their regional neighbors and more with other European countries.

Figure 2

Scientific Cooperation Links between Central Eastern European Countries Compared to Scientific Cooperation Links between Central Eastern European and Other European Countries

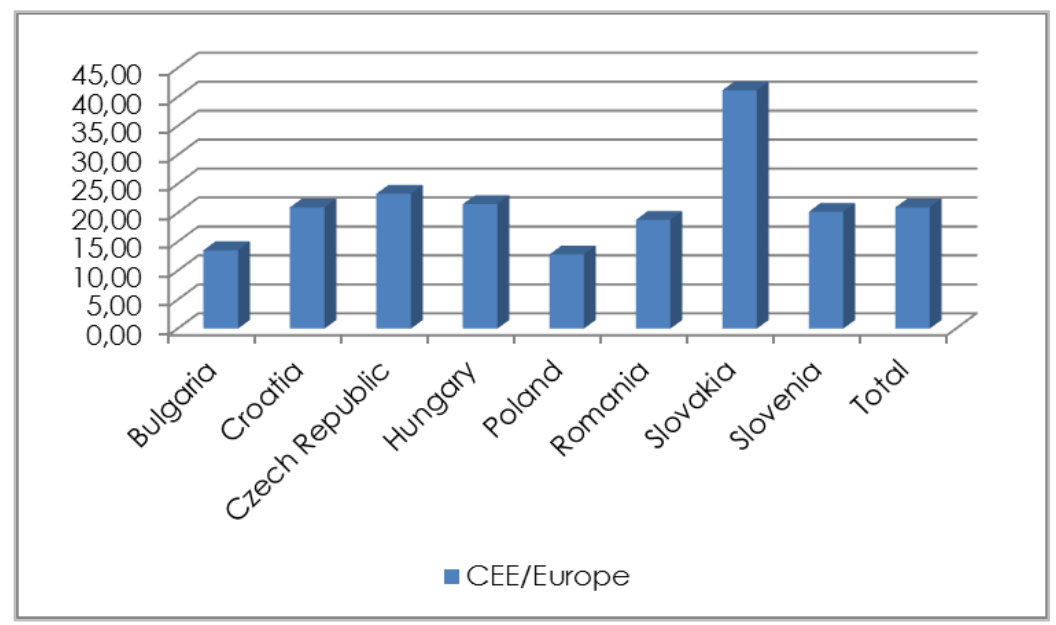

Source: Author's illustration 
The preferred partners for international scientific collaboration in the field of economics are Western European countries such as United Kingdom, Germany or France. This comes as no surprise as many studies highlighted the importance of cooperating with developed countries (see for example Gossart et al., 2009; Sarwar et al., 2015; Wang et al., 2015; Zhou et al., 2015). For developing countries collaborating with developed countries can increase the country's knowledge base and can make joining the international scientific community easier.

Scientific cooperation is measured through publication data. Only those publications were taken in consideration which had in their affiliation at least one Central Eastern European country. The scientific cooperation links of the CEE countries in the field of economics are analyzed using network theory tools. The network is undirected. Countries are the nodes, while the edges are the cooperation links between countries. The size of edges represents the amount of links between countries. The thicker is the edge, the higher is the number of scientific cooperation between the linked nodes (countries). Two countries are linked together when the two countries are both mentioned in the affiliation of at least one publication. This means that not only co-authored publications were taken in consideration, but also single authored publications which had in their affiliation at least two different countries marked. The scientific cooperation network for the CEE countries can be seen on Figure 3.

Figure 3

Scientific Collaboration Networks of Central Eastern European Countries

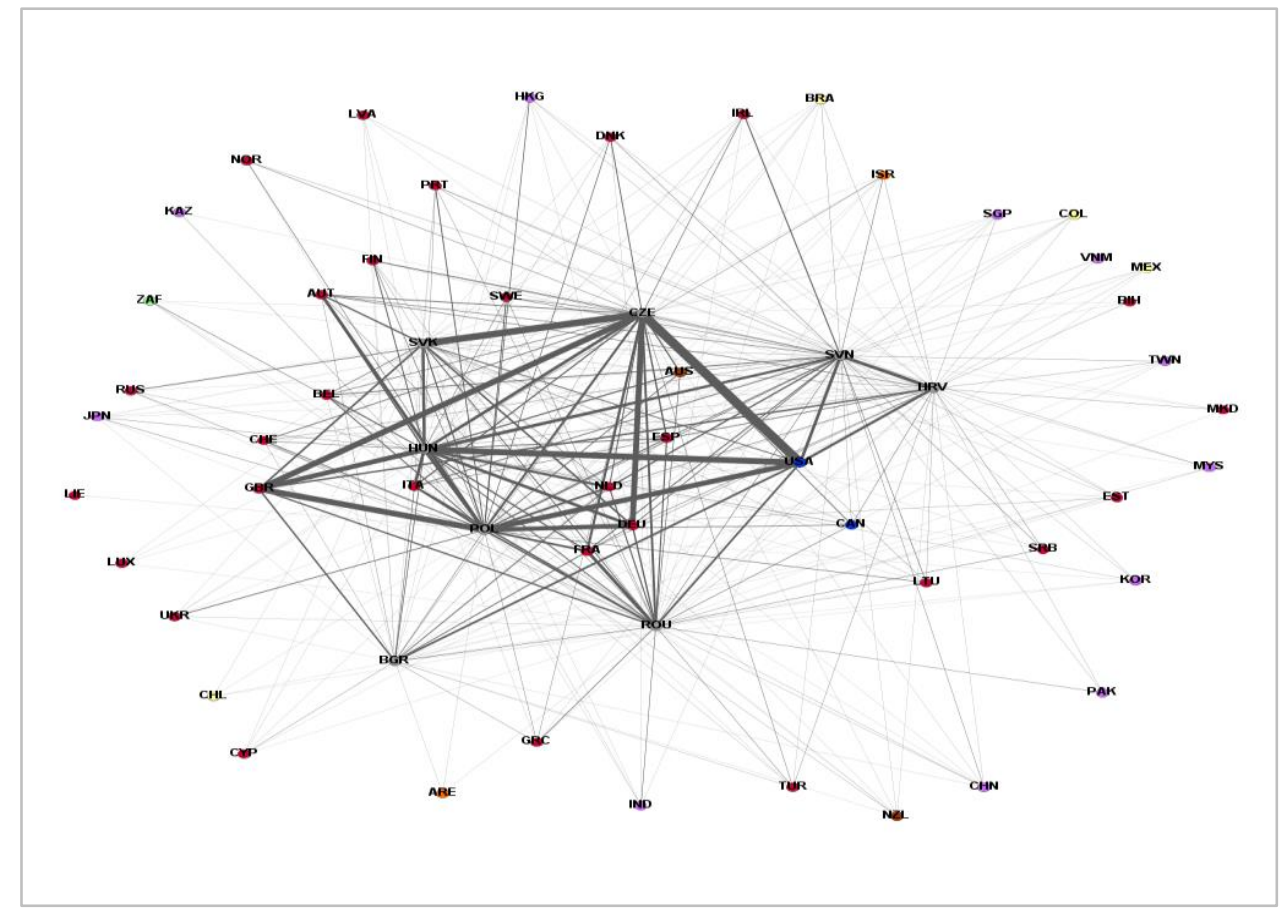

Source: Author's illustration

The edges between Central Eastern European countries and other European countries is the thickest. This is the case especially between CEE (grey nodes) and developed Western European countries (red nodes) and the United States of America and Canada. Scientific cooperation with countries from other continents (except North America) is lesser in number. 
The edges linking CEE countries with other CEE countries are thinner than the edges between CEE and Western European or North American countries. This indicates that in the field of economics Central Eastern European countries prefer to collaborate with developed countries. The countries of the CEE region, when choosing scientific cooperation partners, prefer developed countries to regional neighbors. Geographic distance does not seem to play an important role in scientific collaboration. This is in accordance with the findings of Choi (2012) who concluded that the development of information and transportation technologies not geographical distance influence the co-authorship links between different countries.

The scientific collaboration network (Figure 3.) was analyzed using network theory tools. The network consists of 97 nodes. This means that in the field of economics, the eight CEE countries hadduring 1996-2014 period scientific collaboration resulting in publication with 89 other countries. It is interesting to see which CEE countries have the most scientific links with other countries. Network theory indicators can be used to analyze the network relations of the Central Eastern European countries. The weighted degree and the PageRank are calculated for the eight countries of the CEE region.

The degree shows the number of edges belonging to a node. When the edges are not considered equal, the weighted degree is used (Barabási, 2014). In this study the edges are of different size. They represent different number of publication links, so the weighted degree indicator is used. The highest weighted degree belongs to the Czech Republic (1096). This means that this country was marked in the affiliation of publications most often in the analyzed database. Poland has the second highest value(1051). This is followed by Hungary (959). These countries have the highest number of scientific cooperation links in the region. The countries with the lowest number of links were Bulgaria and Croatia. These two countries are those which have the lowest number of scientific cooperation with other countries in the field of economics.

PageRank is an algorithm used mostly by web search programs. It ranks nodes (in this study, countries) according to the number of links belonging to a node. This indicator can be regarded as a type of prestige measurement (see for example Kumar et al., 2013; Kumar et al., 2014). As expected from the results of the weighted degree values, the countries ranked the highest are the Czech Republic, Poland and Hungary. The countries with the lowest PageRank values in the CEE region are Bulgaria and Croatia.

Looking at the international publication data of the CEE countries, one can see that the Central Eastern European region is not homogeneous. There are more and less open countries regarding their international scientific relations. However, compared to developed countries, the quantity and quality of scientific collaboration links is lagging behind for all countries of this region. The policy decision makers should therefore focus more on research and education mobility and promote the development of scientific collaborations.

\section{Conclusion}

International scientific cooperation can benefit both developing and developed countries. It can ease the creation and diffusion of knowledge and can also enhance the partner countries' scientific performance. In this study the scientific cooperation of the Central Eastern European countries was analyzed. The focus was on the field of economics. Collaborations were measured using publication data. It has been shown that the CEE countries tend to cooperate more with developed, primarily Western European countries than with countries from the region. The Czech 
Republic, Poland and Hungary have the highest number of publication links. The study used publication data for measuring international scientific cooperation. This however is only one aspect of these types of collaborations. Further research would be needed to get a deeper and more accurate picture of the scientific collaboration networks of the Central Eastern European countries.

Using network theory tools to analyze international scientific collaborations can support the development of international scientific cooperation programs. It can also help choosing new international scientific partners. This in turn is of great importance for countries like the ones belonging to the Central Eastern European region as scientific collaborations can have a great effect on the countries' international scientific visibility and performance. Policy decision makers should therefore focus more on supporting and promoting scientific collaborations. These can facilitate the scientific catching-up process.

The study deals with scientific cooperation measured through publications. Using other network and bibliometric tools such as citations or references can further deepen our understanding of scientific links of CEE countries in the field of economics. This may be subject to further research.

\section{References}

1. Barabási, A.-L. (2014), "Network Science", available at: http://barabasilab.neu.edu/networksciencebook/downIPDF.html (4/28/2016)

2. Beaver, D. (2004), "Does collaborative research have greater epistemic authority?", Scientometrics, vol. 60., no. 3., pp. 399-408.

3. Beaver, D., Rosen, R. (1978), "Studies in scientific collaboration", Scientometrics, vol. 1, no. 1, pp. 65-84.

4. Choi, S. (2012), "Core-periphery, new clusters, or rising stars? International scientific collaboration among advanced' countries in the era of globalization", Scientometrics, vol. 90, no. 1, pp. 25-41.

5. Coupé, T. (2004), "What Do We Know About Ourselves? On the Economics of Economics", Kyklos, vol. 57, no. 2, pp. 197-216.

6. European Commission (2014), "Horizon2020 in brief", available at: https://ec.europa.eu/programmes/horizon2020/sites/horizon2020/files/H2020_inBrief_E N_FinalBAT.pdf $(4 / 28 / 2016)$

7. Glänzel, W. (2001), "National Characteristics in International Scientific Coauthorship",Scientometrics, Vol. 51., No. 1., pp. 69-115.

8. Gossart, C., Özman, M. (2009), "Co-authorship networks in social sciences: The case of Turkey", Scientometrics, vol. 78, no. 2, pp. 323-345.

9. Kumar, S., Rohani, V. A., Ratnavelu, K. (2014), "International research collaborations of ASEAN Nations in economics, 1979-2010", Scientometrics, vol. 101., no. 1., pp. 847-867.

10. Kumar, S., Jan, J. M. (2013), "Mapping research collaborations in the business and management field in Malaysia, 1980-2010", Scientometrics, vol. 97., no. 3., pp. 491517.

11. Laudel, G. (2002), "What do we measure by co-authorship?", Research Evaluation, vol. 11., no. 1., pp. 3-15.

12. Lundberg, J., Tomson, G., Lundkvist, I., Skår, J., Brommels, M. (2006), "Collaboration uncovered: Exploring the adequacy of measuring university-industry collaboration through co-authorship and funding", Scientometrics, vol. 69, no. 3, pp. 575-589.

13. Radosevic, S., Yoruk, E. (2014), "Are there global shifts in the world science base? Analysing the catching up and falling behind of world regions", Scientometrics, vol. 101, no. 3, pp. 1897-1924.

14. Sarwar, R., Hassan, S-U. (2015), "A bibliometric assessment of scientific productivity and international collaboration of the Islamic World in science and technology (S\&T) areas", Scientometrics, vol. 105, no. 2, pp. 1059-1077. 
15. Schubert, A., Braun, T. (1990), "International collaboration in the sciences 1981-1985", Scientometrics, vol. 19, no. 1, pp. 3-10.

16. Wang, L., Thijs, B., Glänzel, W. (2015), "Characteristics of international collaboration in sport sciences publications and its influence on citation impact", Scientometrics, vol. 105, no. 2, pp. 843-862.

17. Zhou, P., LV, X. (2015), "Academic publishing and collaboration between China and Germany in physics", Scientometrics, vol. 105, no. 3, pp. 1875-1887.

\section{About the author}

Andrea Magda Nagy graduated at Budapest University of Technology and Economics in 2011. She studied Business Management (specialization: external economics). Currently she is assistant researcher at MTA-PE Networked Research Group on Regional Innovation and Development Studies and PhD student at University of Pannonia. Her research activities focus on competitiveness rankings and scientometric analysis. The author can be contacted at andreamagda.nagy@gmail.com. 